\title{
Belit-Nesheti, cartas da Senhora dos Leões ao rei do Egito: EA 273 e EA 274*
}

\author{
Belit-Nesheti, letters of the Lady of the Lions to the \\ king of Egypt: EA 273 and EA 274
}

\section{Belit-Nesheti, cartas de la Señora de los Leones al rey de Egipto: EA 273 y EA 274}

Leide Jane Soares dos Santos ${ }^{*}$

\begin{abstract}
RESUMO
O objetivo desta pesquisa é fazer análise crítica das cartas da Senhora dos Leões, comparando com as placas de divindades femininas encontradas em Bet-Semes, além de alguns estudos sobre as estruturas das cidades do Sefelá, no período de Amarna. A partir desta pesquisa, é possível levantar questões sobre a localização destas cidades e os conflitos existentes na Sefelá; a importância comercial deste território; o estilo das correspondências dos reis vassalos com o Egito. A região de Gezer, em que as cartas 273-274 foram escritas, ajuda a compreender o domínio dela sobre as cidades vizinhas, as teorias sobre a localização do reino da Senhora dos Leões entre Bet-Semes ou Sapuma e o culto à figura do leão como representação de autoridade, realeza ou divindades dos cananeus cultuadas na época.
\end{abstract}

Palavras-chave: Cartas de Amarna; Senhoras dos Leões; Sefelá; Bet-Semes.

\begin{abstract}
The objective of this research is to make a critical analysis of the letters of the Lady of the Lions, comparing them with the plates of female deities found in BetSemes, besides some studies on the structures of the cities of the Sefela in the period of Amarna. From this research it is possible to raise questions about the location of these cities and the conflicts existing in the Sefelá, the commercial importance of this territory, the style of correspondence of the vassal kings with Egypt, the region of Gezer in which letters 273-274 were written which help to understand her dominion over neighboring cities, theories about the location of the Lions' kingdom between Bet-Semes or Sapuma, and the cult of the lion figure as a representation of authority, royalty, or divinity of the Canaanites worshiped at the time Keywords: Amarna Letters; Lady of the Lions; Sefelá; Bet-Semes.
\end{abstract}

\section{RESUMEN}

El objetivo de esta investigación es hacer análisis crítica de las cartas de la Señora de los Leones, comparando con las placas de divinidades femeninas encontradas en Bet-Semes, además de algunos estudios sobre las estructuras de las ciudades del Sefelá en el período de Amarna. A partir de esta investigación es posible plantear cuestiones sobre la localización de estas ciudades y los conflictos existentes en la Sefelá, la importancia comercial de este territorio, el estilo de las correspondencias de los reyes vasallos con Egipto, la región de Gezer en la que se escribieron las cartas 273-274 que ayudan a comprender su dominio so-

\footnotetext{
* Este artigo é parte da produção de pesquisa realizada durante o ano de 2017 pelo Grupo de Pesquisa "Arqueologia do Antigo Oriente Próximo", da Universidade Metodista de São Paulo - Reg. no CNPq $\mathrm{N}^{\circ} 4338921870858325$.

** Mestranda em Ciências da Religião pela Universidade Metodista de São Paulo (UMESP).
} 
bre las ciudades vecinas, las teorías sobre la ubicación del reino de la Señora de los Leones entre Bet-Semes o Sapuma y el culto a la figura del león como representación de autoridad, realeza o divinidades de los cananeos cultuados en la época.

Palabras clave: Cartas de Amarna; Señoras de los Leones; Shephelah; Bet Shemesh.

\section{Introdução}

Nas cartas de Amarna, a Senhora dos Leões escreve ao rei do Egito sobre ataques em seu território realizados pelos apirus e pede a ele que resgate sua terra das mãos deste grupo. Os apirus são uma classe social presente nos textos antigos dessa região por anos, conhecidos como mercenários disponíveis para contratação visando o próprio lucro, que algumas vezes atacavam e saqueavam as cidades-estato, faziam trabalhos braçais (MAZAR, 2003, p.337) e, neste caso, poderiam ser contratados por quem queria o controle do território. Ao observar as cartas, fica clara a instabilidade do território, mas conflitos diversos aparecem, desde uma grande rebelião contra as cidades-estato, passando por conflitos internos entre as cidades ou até mesmo uma rebelião contra vassalagem ao rei do Egito, já que, no período de Amarna, houve grande instabilidade no território e um caos interno.

Belit nesheti, cujo nome significa Senhora dos leões, também cita em suas cartas algumas cidades tomadas pelos apirus, que estão localizadas na região fértil do Sefelá. São elas: Aijalon, Zorá e uma cidade chamada Sapuma, possivelmente próxima a elas. Além disso, ela cita dois filhos de Milkilu, o governante de Gezer, que quase não sobreviveram ao conflito.

A Sefelá era uma região importante no território, o Egito levava da região de Canaã diversos produtos como madeira, azeite, vinho, gado, cobre, escravos e concubinas (MAZAR, 2003, p.337), e, principalmente, cereais, assim como lhes fornecia material "manufaturado". Para manter essa relação, a Sefelá tinha um papel indispensável: o território era adequado para a agricultura e produzia trigo, uva e oliva em abundância diferente de outras regiões de Canaã.

O comércio também era comum na Sefelá, as cidades não tinham produtos manufaturados em grande quantidade e possuíam uma cerâmica local pouco elaborada. Cerâmica importada foi encontrada nesta região e teria sido produzida em Chipre, assim como o território também importava dos micenas. A arquitetura possuía grande influência egípcia e as características canaanitas se misturavam com sua ornamentação.

O povo desta época vivia um grande sincretismo entre a cultura canaanita e a egípcia, o rei do Egito manteve a estrutura das cidades-estato que tinham a independência estabelecida no período anterior, mas deixou o povo em uma situação de vassalagem e submissão, pagando tributo e dependendo dele (MAZAR, 2003, p.237). Algumas cidades-estado independentes estão na Sefelá, como Gezer, região à qual pertence a Senhora dos Leões. 
Amihai Mazar questiona a pouca evidência de fortificação das cidades no período egípcio, principalmente sendo tempo de grande agitação e insegurança. Ele relata que as cidades-estado eram continuamente destruídas e restauradas, e levanta a hipótese de que o Egito tenha proibido a fortificação pelos governantes cananeus (MAZAR, 2003, P.243).

Cartas da Senhora dos Leões ao rei do Egito $^{1}$

\section{EA 273}

(1-7) Fale ao rei, meu senhor, minha divindade, meu deus sol; A mensagem de "Senhora dos Leões", sua serva: Aos pés do rei, meu senhor, minha divindade, meu deus sol, sete vezes (e) sete vezes caí.

(8-16) Que o rei, meu senhor, seja informado de que a guerra está sendo conduzida na terra e que a terra do rei, meu senhor, é acabada por deserção (ou por meio de) os apiru homens. Assim o rei, meu senhor, seja informado acerca da sua terra.

(16-26) E o rei, meu senhor, seja informado de que os (apiru) homens escreveram (enviaram) para a cidade de Ayalon e para a cidade de Zorá e por uma polegada os dois filhos de Milkilu não foram feridos. Assim o rei, meu senhor, pode ser informado sobre esta ação.

\section{EA 274}

(1-9) Fala ao rei, meu senhor, minha divindade, meu deus Sol; A mensagem de "Senhora dos Leões", sua serva, a sujeira debaixo de seus pés: Aos pés do rei, meu senhor, minha divindade, meu deus Sol, sete vezes (e) sete vezes eu caí.

(10-14) Que o rei, meu senhor, resgate a sua terra da mão dos homens 'apîru, para que não se perca.

(15-16) Conquistada está a cidade de Sapuma.

(17-18) E (isto é) para a informação do rei, meu senhor.

\section{Escrita padronizada}

As cartas da Senhora dos Leões, diferente dos grandes povos que tinham diplomacia com o Egito, fazem parte do grupo de cartas das cidades vassalas, por isso têm essa fórmula de humilhação como característica (MINAROVA, 2005, P.397-406).

Outro motivo para a semelhança na escrita é o fato de pertencerem à mesma região. Rainey afirma que o barro da carta 273 foi produzido em Laquis e trazido para Bet-Semes, perto do sudoeste do reino de Gezer (RAINEY, 2015, v. 1, P. 1583). Goren, Finkelstein e Na'aman, na análise petrográfica, concluem que as cartas foram produzidas em Gezer, planície costeira do vale de Aijalon e tem semelhança com as cartas de Shuwardarta (EA 278-280), Shum- [..] (EA 272), YaÆzib-Adda (EA 275-276), uma carta

\footnotetext{
A tradução foi realizada a partir dos seguintes textos em inglês: MORAN, William L. (ed. e trad.). The Amarna Letters. Baltimore: The John Hopkins University Press, 1992; e RAINEY, Anson F. (org. e trad.). The El-Amarna Correspondence: a new edition of the Cuneiform Letters from the site of El-Amarna based on collations of all extant tablets. Edição de William M. Schniedewind. Leiden: Brill, 2015.
} 
de Tagi (266) e uma carta de YaÆtiru (EA 296). Algumas delas enviadas de Gezer e outras de cidades vizinhas, mas tendo em comum a escrita. Possivelmente, o mesmo escriba escreveu as cartas em nome dos governantes e viajava entre as cidades vizinhas aliadas de Gezer ou, em algumas ocasiões, os reis escreveram desde Gezer. Existe a hipótese da carta 273 ter sido enviada a partir de Gezer. É de se pensar que nesta cidade havia escribas operando. Ao que parece, escrever em acádio não era algo comum, usado apenas para relações internacionais, forçando os governantes a buscar escribas especializados em cidades vizinhas (GOREN, FINKELSTEIN, NA'AMAN, 2004, p.270-279). Talvez uma escola de escribas residindo em Gezer usasse um estilo padrão para todas as cartas.

É possível observar no quadro abaixo que ambas as cartas de Belit-Neshet possuem uma mesma estrutura. As demais cartas feitas no território de Gezer são muito semelhantes: ou havia um padrão para as correspondências com o Egito ou foram feitas pelo mesmo escriba.

\begin{tabular}{|l|l|l|l|}
\hline EA & INTRODUÇÃO & CONTEÚDO & \multicolumn{1}{c|}{ CONCLUSÃO } \\
\hline $\mathbf{2 7 3}$ & $\begin{array}{l}\text { Identificação } \\
\text { e fórmula de } \\
\text { prostração }\end{array}$ & $\begin{array}{l}\text { 8-26- relata o ataque } \\
\text { ao território do rei } \\
\text { pelos apirus e que eles } \\
\text { ameaçam as cidades de } \\
\text { Ayalon e Zorah em que } \\
\text { dois filhos de Milkilu } \\
\text { quase morreram. }\end{array}$ & $\begin{array}{l}\text { Justificativa: escreve } \\
\text { para que o rei tome } \\
\text { conhecimento do que } \\
\text { acontece no território. }\end{array}$ \\
\hline $\begin{array}{l}\text { EA } \\
\mathbf{2 7 4}\end{array}$ & $\begin{array}{l}\text { Identificação } \\
\text { e fórmula de } \\
\text { prostração }\end{array}$ & $\begin{array}{l}\text { 10-16- Pede ao rei } \\
\text { do Egito que recupere } \\
\text { a terra tomada pelos } \\
\text { apirus e informa que a } \\
\text { cidade de Sapuma foi } \\
\text { conquistada. }\end{array}$ & $\begin{array}{l}\text { escreve para que o rei } \\
\text { tome conhecimento } \\
\text { do que acontece no } \\
\text { território. }\end{array}$ \\
\hline
\end{tabular}

\section{Conflito no território}

Belit-Nesheti informa ao rei sobre a guerra no território e cita as cidades de Ayalon e Zorá que correm perigo, relata também o ocorrido com os dois filhos de Milkilu, que quase não escaparam com vida. Milkilu era governante de Gezer e autor de cinco das cartas de Amarna (267-271). A carta EA 369 é do rei do Egito a Milkilu, referindo-se a relações comerciais. Yapa'u é seu herdeiro e reinou em Gezer após a morte do pai por um curto tempo. $\mathrm{Na} E A$ 298, Yapa'u se queixa de que seu irmão mais novo se rebela contra ele (GOREN, FINKELSTEIN, NA'AMAN, 2004, p.270-279). Sabendo que Gezer controlava uma vasta região do Sefelá e tinha destaque no período de 
Amarna, conclui-se que as cidades vizinhas deveriam ser influenciadas por Gezer e Belit-Nesheti seria aliada da casa de Milkilu.

Definir a essência dos conflitos em Canaã narrados nas cartas de Amarna é difícil. No caso da Sefelá, nota-se que as cartas endereçadas ao rei do Egito são, em sua maioria, para pedir exército, administrar o comércio, informar sobre os passos tomados pelos governantes e pedir permissões ao rei para prosseguir nas estratégias de combate. A EA 290, de Abdi-Heba, governante de Jerusalém, ilustra bem o conflito da região. Ele pede ao rei do Egito que mostre preocupação por sua terra, pois Milkilu, de Gezer, e Shuwardata, de Gath, junto com tropas de Qilti (Keilah), se juntaram para combater contra Abdi-Heba e os apirus, que trabalhavam para eles, já haviam conquistado uma cidade no território de Jerusalém. Paralelo a esta informação, as EA 278-284, 366 de Shuwardata estão endereçadas ao rei do Egito pedindo tropas para lutar contra Abdi-Heba e informando sobre a desordem em seu território, a traição e sua possível perda do controle. Shuwardata relata que está sozinho e pede que o rei o retire do território para que ele se livre de seu destino.

É interessante observar que, apesar do caos entre as cidades vizinhas por território, existem em Gezer cartas comerciais, tanto de Milkilu, enviando servos e servas para o rei (EA 268), quanto do Egito, encomendando mulheres bonitas para servir como copeiras (EA 369). Parece que os vassalos do rei brigam entre si disputando territórios, enquanto o rei administra a situação sem tomar partido de nenhum lado, ou simplesmente perdeu o controle de seu reino.

\section{Localização}

$\mathrm{Na} E A$ 273, Belit-Nesheti comunica que a terra do rei está em guerra, invadida e saqueada pelos apirus e na E $A 274$ pede ao rei que resgate a terra dele para que não se perca e dá a notícia de que a cidade de Sapuma foi saqueada.

Existe uma discussão sobre qual seria a cidade de procedência da Senhora dos Leões. É claro que Sapuma pertence à região da Sefelá, as cidades citadas nas cartas estão situadas nesta região e a análise petrográfica também afirma que as mesmas foram produzidas e escritas no mesmo lugar. A problemática é de onde veio Belit-Nesheti e qual sua função nesta região?

Sapuma foi identificada possivelmente como a aldeia Saffa, na fronteira de Gezer, ou talvez em EL-Burj, que está a $3 \mathrm{Km}$ de Saffa e tem um monte que ainda não foi escavado (GOREN, FINKELSTEIN, NA'AMAN, 2004, p.270-279). Mas não se sabe se Belit-Nesheti governava em Sapuma ou em outra cidade. Mesmo que a EA 273 tenha saído de Gezer, é descartada a hipótese de que ela seja rainha ou rainha-mãe nesta cidade, pois se refere aos 
filhos de Milkilu em terceira pessoa (GOREN, FINKELSTEIN, NA'AMAN, 2004, p.270-279). O consenso entre os estudiosos é que Belit-Nesheti governou alguma cidade vizinha.

Bet-semes é defendida como a possível cidade da Senhora dos Leões e o relato dela nas cartas seria uma preocupação sobre a situação de seu território. A cidade era bem desenvolvida no período de Amarna, em relação às outras cidades do interior da Sefelá e, assim como o resto do território, também sofreu com a agitação e caos interno do governo Egípcio, no tempo de Amarna. Pouco depois de 1350 a.C., a cidade foi devastada e incendiada.

Nas escavações realizadas na cidade, foram encontrados entre os tijolos marcados pelo fogo um número enorme de flechas, indicando que houve muita luta antes da conquista da cidade. Além disso, a cidade estava cheia de pertences cotidianos, indicando que o povo fugiu (ZIFFER, BUNIMOVITZ, \& LEDERMAN, 2009 p. 333-341). Contudo, se as cartas, segundo a análise petrográfica, foram enviadas de Gezer e escritas pelo mesmo escriba que as demais cartas confirmadas como originais de Gezer, é estranho que ela precise sair de seu território, sendo Bet-Semes uma cidade organizada e com escrita desenvolvida.

Em 1928-1933, a expedição americana do Haverford College datou achados do Bronze II (séculos 14 e 13 a.E.C.). Dentre eles, encontrou-se cerâmica local e importada de Cipro e dos Micenas, além de jóias, cisternas, tumbas, casas em ruínas, escaravelhos, peças egípcias. O mais impressionante é a descoberta de uma tabuinha cuneiforme escrita com o alfabeto ugarítico e um ôstraco com inscrição proto-canaanita (ZIFFER, BUNIMOVITZ, \& LEDERMAN, 2009, p. 333-341). Com estas informações, é difícil pensar que Belit-Nesheti precisaria sair de Bet-Semes para escrever as cartas e receber ajuda do escriba especializado, se não for pelo fato de existir um centro próprio em Gezer ou caso seu território já tenha sido tomado pelos apirus. Neste caso, a Senhora dos Leões está informando ao rei a perda de seu território.

\section{Bet-Semes ou Sapuma?}

É realmente provável que Belit-Nesheti tenha governado em Bet-Semes, mas fica a pergunta de por que ela escreve ao rei do Egito relatando a queda de cidades vizinhas?

Dizer que o rei deve resgatar a terra para que não se perca e, em seguida, informar que Sapuma foi tomada (EA 274, 10-16) pode ser devido ao medo de que os apirus também devastem sua cidade. Assim, ela se antecipa, informando e pedindo a intervenção do rei, pois, possivelmente, estariam os apirus tomando o território cidade por cidade ou vindo do norte, já que 
Sapuma, Aijalon e Zorá estão ao norte de Bet-Semes. Belit-Nesheti também podia ter se refugiado em Gezer, caso sua cidade já tivesse caído. Neste caso, como ela se refere à queda de Sapuma, que está próxima de Gezer, então o provável é que ela se refira à queda de sua própria cidade ou de uma cidade que está em seu território. E ela precisa da intervenção do rei antes que todo o território caia. É possível que ela tenha governado em uma cidade próxima ou na própria Sapuma e não Bet-Semes.

\section{Bet-Semes}

O significado de Bet-Semes é "casa do sol". Então, o deus sol do Egito (Amon-Rá ou Atom) provavelmente era a divindade principal cultuada na cidade e, assim como as demais cidades, ela sofria influência do Egito nos costumes e cultos religiosos, gerando um grande sincretismo.

Escavações em Tel Bet-Semes, lideradas por Shlomo Bunimovitz e Zvi Lederman do Instituto de Arqueologia da Universidade de Tel Aviv, encontraram uma placa de cerâmica de uma mulher vestindo roupas reais masculinas. A placa mostra algo comum na arte egípcia e Cananeia: a mulher está em pé sob uma cesta, o penteado da figura é feminino e ela segura uma flor de lótus (ZIFFER, BUNIMOVITZ, \& LEDERMAN, 2009, p. 333-341). O nome de Belit-Nesheti significa "Senhora dos Leões", um predador comumente relacionado ao poder, à autoridade, à realeza e às divindades dos cananeus, como Baal, El e Anat, bem como representação comum em todo o Oriente e Mediterrâneo, assim como na arte Egípcia.

Nos templos e nas cerimônias canaanitas, a imagem do leão era usada, em Alalakh e Hazor. A entrada do templo era guardada por ortostatos leoninos. Também em Hazor o altar encontrado tinha um leão que guardava a entrada. Em Meguido também se achou uma caixa de cosméticos com a representação de leões e esfinges em auto relevo (MAZAR, 2003, P.249-271).

Segundo Mazar, representações egípcias e cananeias de uma deusa nua em pé sobre um leão era algo bem comum. Essa deusa era identificada no Egito como Qudshu, que significa "a sagrada”.

No templo de Laquis foi encontrada uma variação desta figura presente em uma lâmina de ouro, a deusa aparece de perfil, usando uma coroa egípcia, e está em pé sob um cavalo com duas flores de lótus nas mãos (MAZAR, 2003, P.271). Talvez seja até a mesma deusa encontrada em Bet-Semes com a flor de lótus.

Senhora dos Leões poderia, então, ser um nome dedicado a alguma divindade cananeia, talvez Anat. Pelos achados nas representações, talvez a cidade em que Belit-Nesheti governava fosse dedicada a esta divindade, por 
isso ela se apresentava como Senhora do Leões e não usava o nome da cidade. Mas, também, Senhora dos Leões pode ser uma forma para denotar poder, pois seria ela uma mulher poderosa e de êxito, rainha ou ao menos da nobreza.

Uma rainha em Beth-Shemesh? Em Canaã, as figuras de barro são encontradas principalmente em detritos urbanos, dentro de áreas de habitação, armazenamento e atividades artesanais, em ruas, piscinas e cisternas. Isto também é verdade para a nossa estatueta. Suas imagens devem ter sido significativas para os habitantes de Beth-Shemesh. Divina ou mortal: cujo retrato nossa placa comemora? Pode ser um deus local. No entanto, também pode representar um governante local da época (ZIFFER, BUNIMOVITZ, \& LEDERMAN, 2009 p. 333-341).
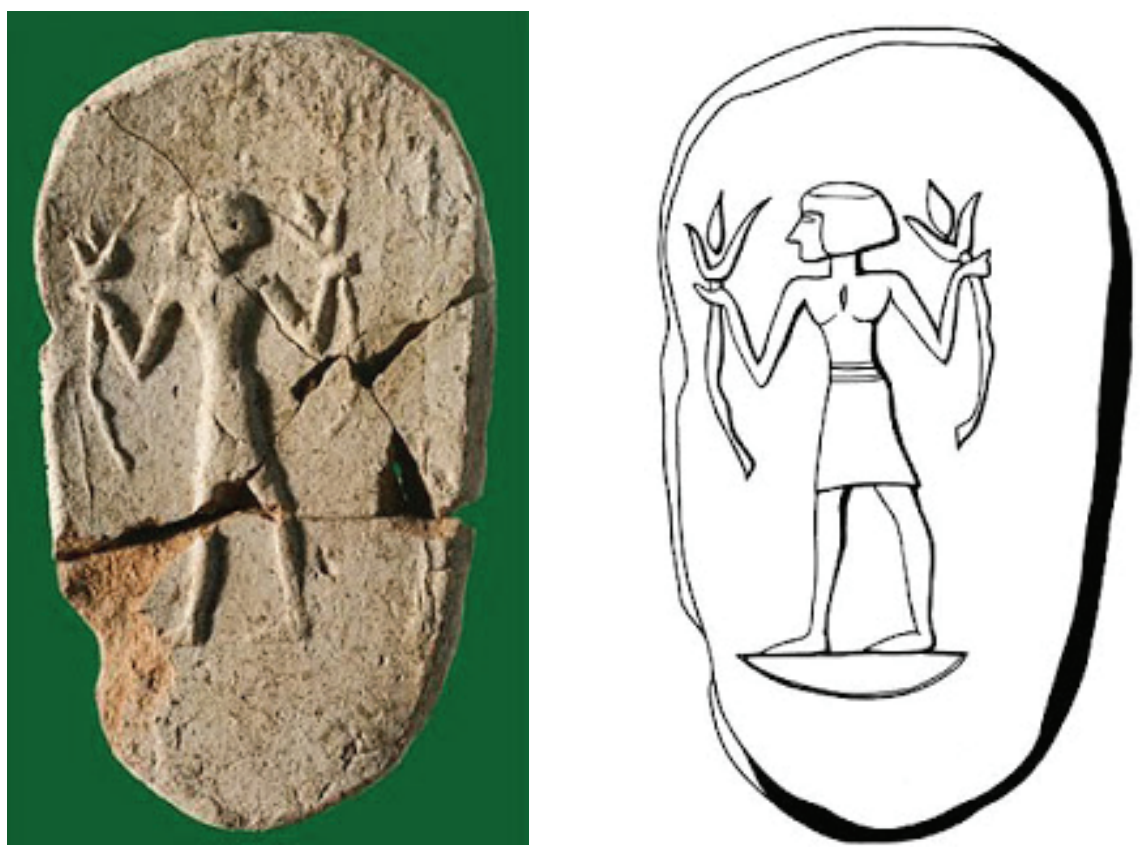

Figura 1: Placa de cerâmica encontrada em Bet-Semes Fonte: Zenobia

Caso estas informações e a hipótese de que Beliti-Nesheti governou em Bet-Semes seja confirmada, esta placa representaria a única governante mulher conhecida na região, pois não há registros de que outra mulher tenha reinado; tão conhecida que, ao enviar as cartas não precisou informar o nome da cidade que pertencia, mas só seu nome já bastava. Então, seria possível que uma mulher, rainha e poderosa, possa ter governado a cidade? E governou com direito próprio? A placa sugere que seja possível, mas poderia ser apenas mais uma representação de culto às divindades femininas presentes em Canaã. 


\section{Governante mulher}

Independente da cidade de governo ou o poder que ela exercia, ter uma governante mulher de uma região importante de Canaã, como a Sefelá, em época de instabilidade no território, em 1350 a.E,C. aproximadamente, é algo notável. Talvez existissem outras rainhas e governantes de cidades na região que não deixaram registros.

O importante é perceber que, em algum lugar, neste período tão opressor, existiu uma mulher que teve um papel de destaque além da reprodução, criação e educação dos filhos, do cuidado com os idosos e doentes, da exploração, escravidão e comercialização de seu corpo e força de trabalho.

Tea Frigerio (1991, p.79-81), em um estudo, organizou a presença das mulheres de maneira global a partir de vários contextos da vida no período inicial de Israel, e concluiu que a mulher é vista apenas como reprodutora de mão-de-obra.

Segundo a autora, a mulher não tem seu devido valor nos vários níveis da organização social. Como ela bem descreve: no nível econômico, a mulher não é incluída no processo de produção, ela apenas reproduz; no político, a liderança masculina prevalece, mas existem algumas que não são totalmente passivas; no social, a presença da mulher é marcante, tem práticas e ações significativas, gerenciam e garantem a vida do grupo; no cultural, são elas que transmitem a memória e os costumes, já que ficam nas tendas, amamentam e criam os filhos; e, no âmbito religioso, vê-se que a mulher tem grande participação, pois, a partir de sua realidade, refletiram sobre Deus e expressaram sua fé, matriarcas que perceberam e revelaram o rosto de Deus que haviam experimentado (FRIGERIO, 1991, P. 79-81).

Há muitos casos em que as mulheres deste período eram consideradas seres sagrados, frequentemente divinizados em relação à sua sexualidade, fertilidade, características maternas ou domésticas, como vemos nas diversas representações das deusas da fertilidade. Uma imagem pequena, pois seu destaque no meio social era incontestável, estavam presentes nos campos de batalha, na agricultura, e ainda eram responsáveis pela educação e crescimento da população, mas foram reduzidas a seres fracos e sem valor.

Um motivo que ajudou a construir essa imagem da mulher foi que, após o terceiro milênio a.E.C., as populações diminuíram e a expectativa de vida era de 40 anos de idade. A população morria em grandes quantidades, possivelmente por doenças ou guerras (MARIANO, 2008, p. 158-159). Devido a isso, a iniciativa foi poupar as mulheres de ambientes perigosos e conservá-las apenas em atividades domésticas e na geração de filhos e filhas para garantir a preservação do povo ao qual pertenciam (MARIANO, 2008, P. 158-159). 
Uma personalidade como a Senhora dos Leões é incomum para o conceito que temos hoje sobre a vida destes povos antigos. Uma mulher lembrada na história por quem ela era, e não por sua ligação com algum homem, pode parecer estranho para muitos. Possivelmente, no período de Amarna, como ao longo da história, houvesse muitas outras como ela, mas que permaneceram no anonimato.

\section{Referências bibliográficas}

GOREN, Yuval; FINKELSTEIN, Israel; NA'AMAN, Nadav. Inscribed in clay: provenance study of the Amarna letters and the other ancient Near Eastern texts. Tel Aviv: Emery and Clair Publications in Archaeology, 2004.

MAZAR, Amihai. Arqueologia na terra da Biblia: 10.000-586 a.C. São Paulo, Paulinas, 2003. MARIANNO, Lília Dias. Profetisas no antigo Israel: entre um conselho e outro, interferindo no curso da história. Revista de Interpretação Bíblica Latino-Americana, Petrópolis, vol. 60, p. 158-166, 2008.

MORAN, William L. (ed. e trad.). The Amarna Letters. Baltimore: The John Hopkins University Press, 1992.

MYNAROVA, Jana. A comment on the opening passages of the Amarna letters: its structure and its addres. Archiv orienálni - Quaterly Journal of African and Asian Studies, vol. 73, 2005 .

RAINEY, Anson F. (org. e trad.). The El-Amarna correspondence: a new edition of the cuneiform letters from the site of El-Amarna based on collations of all extant tablets. Edição de William M. Schniedewind. Leiden: Brill, 2015.

ZIFFER, I., BUNIMOVITZ, S., \& LEDERMAN, Z. Divine or human? An intriguing Late Bronze Age plaque figurine from Tel Beth-Shemesh. Egypt and the Levant, vol. 19, p. 333341, 2009. 